\title{
Association analysis of the IGF1 gene with childhood growth, IGF-1 concentrations and type 1 diabetes
}

\author{
A. Vella $\cdot$ N. Bouatia-Naji $\cdot$ B. Heude $\cdot$ J. D. Cooper $\cdot$ \\ C. E. Lowe $\cdot$ C. Petry $\cdot$ S. M. Ring $\cdot$ D. B. Dunger • \\ J. A. Todd $\cdot$ K. K. Ong
}

Received: 7 December 2007 / Accepted: 2 February 2008/Published online: 4 March 2008

(C) The Author(s) 2008

\begin{abstract}
Aims/hypothesis Insulin-like growth factor-1 is a major childhood growth factor and promotes pancreatic islet cell survival and growth in vitro. We hypothesised that genetic variation in IGF1 might be associated with childhood

A. Vella and N. Bouatia-Naji contributed equally to this work.

Electronic supplementary material The online version of this article (doi:10.1007/s00125-008-0970-7) contains supplementary material, which is available to authorised users.
\end{abstract}

A. Vella $\cdot$ J. D. Cooper $\cdot$ C. E. Lowe $\cdot$ J. A. Todd Juvenile Diabetes Research Foundation/Wellcome Trust Diabetes and Inflammation Laboratory, Department of Medical Genetics, Cambridge Institute for Medical Research,

University of Cambridge, Cambridge, UK

N. Bouatia-Naji $\cdot$ B. Heude $\cdot$ K. K. Ong $(\square)$

MRC Epidemiology Unit, Institute of Metabolic Science,

Addenbrooke's Hospital P.O. Box 285,

Cambridge CB2 0QQ, UK

e-mail: ken.ong@mrc-epid.cam.ac.uk

B. Heude

INSERM Unit 780, IFR69,

Villejuif, France

B. Heude

Faculty of Medicine, University Paris-Sud,

Orsay, France

C. Petry $\cdot$ D. B. Dunger $\cdot$ K. K. Ong

Department of Paediatrics,

University of Cambridge, Cambridge, UK

S. M. Ring

Department of Community-Based Medicine,

University of Bristol, Bristol, UK

Present address:

A. Vella

Mayo Clinic, Rochester, MN, USA growth, glucose metabolism and type 1 diabetes risk. We therefore examined the association between common genetic variation in $I G F 1$ and predisposition to type 1 diabetes, childhood growth and metabolism.

Materials and methods Variants in IGF1 were identified by direct resequencing of the exons, exon-intron boundaries and $5^{\prime}$ and $3^{\prime}$ regions in 32 unrelated type 1 diabetes patients. A tagging subset of these variants was genotyped in a collection of type 1 diabetes families $(3,121$ parent-child trios). We also genotyped a previously reported CA repeat in the region $5^{\prime}$ to $I G F 1$. A subset of seven tag single nucleotide polymorphism (SNPs) that captured variants with minor allele frequency (MAF) $\geq 0.05$ was genotyped in 902 children from the Avon Longitudinal Study of Parents And Children with data on growth, IGF-1 concentrations, insulin secretion and insulin action.

Results Resequencing detected 27 SNPs in IGF1, of which 11 had a MAF $>0.05$ and were novel. Variants with $\mathrm{MAF} \geq 0.10$ were captured by a set of four tag-SNPs. These SNPs showed no association with type 1 diabetes. In children, global variation in IGF1 was weakly associated with IGF-1 concentrations, but not with other phenotypes. The CA repeat in the region $5^{\prime}$ to $I G F 1$ showed no association with any phenotype. Conclusions/interpretation Common genetic variation in IGF1 alters IGF-1 concentrations but is not associated with growth, glucose metabolism or type 1 diabetes.

Keywords Children · Genetic variation · Growth · IGF-1 · Insulin-like growth factor- $1 \cdot$ Microsatellite $\cdot$ Single nucleotide polymorphism $\cdot$ SNP $\cdot$ Tag-SNPs $\cdot$ Type 1 diabetes

\begin{tabular}{|c|c|}
\hline Abbrevia & ions \\
\hline ALSPAC & Avon Longitudinal Study of Parents And \\
\hline MAF & minor allele frequency \\
\hline
\end{tabular}


SNP single nucleotide polymorphism

WTCCC Wellcome Trust Case Control Consortium

\section{Introduction}

Type 1 diabetes is a common autoimmune disorder that arises by an interaction between genes and the environment. To date, ten loci have been identified including the HLA class II genes, the cytotoxic T-lymphocyte associated protein 4 (CTLA4) locus, protein tyrosine phosphatase, non-receptor type 22 (lymphoid) (PTPN22), IL-2 receptor, alpha (IL2RA), interferon induced with helicase $\mathrm{C}$ domain 1 (IFIH1) and four novel loci identified by a genome-wide association study [1].

The protein products of these genes play important roles in antigen presentation and the cellular immune response, highlighting the importance of the immune system in the pathogenesis of type 1 diabetes. However, not all patients with evidence of islet autoimmunity develop complete beta cell failure [2]. Given the evidence to suggest that early weight gain and growth in childhood are associated with type 1 diabetes [3], it is possible that factors influencing insulin action (body weight and fat mass) and islet function may predispose to or influence the presentation of type 1 diabetes.

Lower IGF-1 concentrations predict the development of glucose intolerance in adults [4]. George et al. reported that islet overexpression of $I G F 1$ in diabetic mice enabled islet regeneration and gradual correction of hyperglycaemia and hypoinsulinaemia [5]. A microsatellite in the region $5^{\prime}$ to $I G F 1$ has been associated with adult height, cardiovascular risk, osteoporosis and type 2 diabetes in some [6] but not all [7] studies.

Since common variation in IGF1 could alter circulating IGF-1 concentrations and therefore body habitus, insulin action and beta cell secretion, we sought to determine the associations, if any, between IGFI and circulating IGF-1 concentrations, size at birth, both fasting and postprandial insulin concentrations, and type 1 diabetes.

\section{Materials and methods}

Polymorphism identification

DNA samples from 32 randomly selected type 1 diabetic probands were amplified using specifically designed forward and reverse primers. This provided $88 \%$ probability of detecting single nucleotide polymorphisms (SNPs) with minor allele frequencies (MAF) of $0.033,96 \%$ probability for MAF 0.05 and $99.8 \%$ for MAF 0.10 [8]. Resequencing included the $3 \mathrm{~kb}$ region $5^{\prime}$ to the gene, all exons and exon-intron boundaries and $3^{\prime}$ untranslated region. Four $1 \mathrm{~kb}$ segments in the second intron, $\sim 10 \mathrm{~kb}$ intervals apart, were also resequenced.
Tag-SNP selection

The resequencing genotype data were used to select SNP subsets that predicted the genotypes of the remainder, using a coefficient of determination, $R^{2}$, which measures the ability to predict each known SNP genotype by linear regression on the tag-SNP genotypes [9]. We considered only SNPs with a $\mathrm{MAF} \geq 0.10$ in the type 1 diabetes collection and $\geq 0.05$ in the Avon Longitudinal Study of Parents And Children (ALSPAC) cohort (for details see below and Electronic supplementary material [ESM]), using a minimum $R^{2}$ of 0.8 .

\section{Genotyping}

All genotyping data were double-scored to minimise error. All genotypes were in Hardy-Weinberg equilibrium $(p>0.05)$.

\section{Populations studied}

All DNA samples were collected after ethics approval and informed consent had been obtained.

Type 1 diabetes family collection Type 1 diabetes families were of white European descent, with two parents and at least one affected child. The populations studied have been described previously [8].

ALSPAC Details of this birth cohort are available on the ALSPAC website (www.alspac.bris.ac.uk). The children in this study are from a $10 \%$ 'Children in Focus' sub-cohort (1,335 full-term singleton infants) randomly selected from the last 6 months of recruitment for more detailed measurements of growth. Birthweight was noted from hospital records, and length and head circumference were measured after birth. At age 7 years (mean age $7.5 \pm 0.1$ years), body weight and height were measured. Body composition was assessed at age 9 years by whole-body dual-energy X-ray absorptiometry. Internal SD scores were calculated for all parameters of growth to adjust for age and sex. IGF-1 concentrations were measured in cord blood samples (birth) and in venous blood (7 or 8 years of age). Fasting insulin sensitivity was assessed by the homeostatic model assessment index (www.dtu.ox.ac. $\mathrm{uk} / \mathrm{homa} /$ ) and insulin secretion at $30 \mathrm{~min}$ post oral glucose by the insulinogenic index at age 8 years.

Statistical analysis

All statistical analyses to test the association between $I G F 1$ and type 1 diabetes were performed in either Stata (www. stata.com/) or R (www.r-project.org/) statistical systems. Additional routines may be downloaded (www-gene.cimr. cam.ac.uk/clayton/software/). Missing tag-SNP genotypes 
were imputed under the null hypothesis and were analysed using a multilocus test [9]. The microsatellite, 5' IGF1 CA repeat, was analysed using TRANSMIT [10]. The global effect of the IGF1 tag-SNP set on each outcome variable was entered into a multi-locus regression model. $R^{2}$ change was taken as the contribution to the total variation in each outcome. Associations of IGF1 SNPs with growth and metabolic phenotypes were analysed using univariate ANOVA (general linear models). The association of the 5' IGF1 CA repeat was analysed by comparing the wild-type allele (192 bp) to all other alleles [6, 7].

For further details on Materials and methods section, see ESM.

\section{Results}

Genetic variation in $I G F 1$

Resequencing identified 27 novel polymorphisms consisting of 24 SNPs, one rare non-synonymous SNP in exon 3 (Ala to Thr) and two deletion/insertion polymorphisms. Eleven SNPs had a MAF $>0.05$. Four tag-SNPs (Table 1) were selected and genotyped in the type 1 diabetes families studied. In ALSPAC, seven tag-SNPs were selected (ESM Table 1).
$I G F 1$ and type 1 diabetes

The selected tag-SNPs were genotyped in 2,439 families (3,121 parent-child trios). The multilocus test of the IGF1 tag-SNPs provided no evidence of an association with type 1 diabetes $\left(\chi_{4}{ }^{2}=4.4 ; p=0.356\right.$; Table 1$)$. The microsatellite, 5' IGF1 CA repeat, was genotyped in 2,109 families and analysed using TRANSMIT [10]. There was no evidence of association $(p=0.358)$ (ESM Table 2$)$.

\section{Wellcome Trust Case Control Consortium data}

We used data from the Wellcome Trust Case Control Consortium (WTCCC) genome-wide association study [1] to test association of the extended $I G F 1$ region with type 1 diabetes. The region contained 22 SNPs. When the WTCCC data were analysed using a logistic regression model adjusted for variation in allele frequencies across Great Britain, no evidence of association of these SNPs within the region was found (ESM Table 3).

\section{Association with IGF-1 concentrations}

In the ALSPAC children, multilocus regression models showed that the IGF1 tag-SNP set was associated with IGF1 protein levels at birth $\left(R^{2}=0.063 ; p=0.029\right)$ and weakly

Table 1 A summary of IGF1 tag-SNPs genotyped in 2,396 families

\begin{tabular}{|c|c|c|c|c|}
\hline \multirow[t]{2}{*}{ Parameter } & \multicolumn{4}{|l|}{ Tag-SNP } \\
\hline & rs $35140968^{\mathrm{a}}$ & rs6214 & rs 3730220 & s6219 \\
\hline Sequence & $\begin{array}{l}\text { AAATAACT[-/AT] } \\
\text { CTCAAATA }\end{array}$ & $\begin{array}{l}\text { GACTTAAC[A/G] } \\
\text { TGTTTTCT }\end{array}$ & $\begin{array}{l}\text { CAGGTTGG[A/T] } \\
\text { CTCAAACT }\end{array}$ & $\begin{array}{l}\text { AACCTCAA[A/G] } \\
\text { CTGTCTAC }\end{array}$ \\
\hline $\begin{array}{l}\text { Allele coding, } \\
1 \text { (minor) } / 2\end{array}$ & Ins/Del & $\mathrm{A} / \mathrm{G}$ & $\mathrm{T} / \mathrm{A}$ & $\mathrm{A} / \mathrm{G}$ \\
\hline MAF in parents & 0.277 & 0.443 & 0.493 & 0.0769 \\
\hline \multicolumn{5}{|l|}{$\begin{array}{l}\text { Minor allele } \\
\text { transmissions }\end{array}$} \\
\hline Transmitted & 815 & 1309 & 915 & 446 \\
\hline Untransmitted $^{\mathrm{b}}$ & 790 & 1386 & 942 & 446 \\
\hline \multicolumn{5}{|l|}{ Genotype $2 / 2$} \\
\hline Transmitted & $1,150(53.1)$ & $947(33.3)$ & $798(33.0)$ & $2,501(84.8)$ \\
\hline Untransmitted $^{\mathrm{b}}$ & $3,478(53.6)$ & 2,724 (31.9) & $2,352(32.4$ & $7,489(84.6)$ \\
\hline \multicolumn{5}{|l|}{ Genotype 2/1 } \\
\hline Transmitted & $849(39.2)$ & $1,382(48.5)$ & $885(36.6)$ & $423(14.3)$ \\
\hline Untransmitted $^{\mathrm{b}}$ & $2,541(39.1)$ & $4,226(49.5)$ & $2,685(37.0)$ & $1,297(14.7)$ \\
\hline \multicolumn{5}{|l|}{ Genotype 1/1 } \\
\hline Transmitted & $166(7.7)$ & $519(18.2)$ & $737(30.5)$ & $27(0.91)$ \\
\hline Untransmitted $^{\mathrm{b}}$ & $476(7.3)$ & $1,594(18.7)$ & $2,223(30.6)$ & $67(0.8)$ \\
\hline $\begin{array}{l}\text { OR for minor allele } \\
(95 \% \mathrm{CI})\end{array}$ & $1.03(0.93-1.14)$ & $0.94(0.87-1.01)$ & $0.97(0.89-1.06)$ & $1.00(0.88-1.14)$ \\
\hline
\end{tabular}

${ }^{\mathrm{a}}$ Deletion/insertion polymorphism

${ }^{\mathrm{b}}$ Untransmitted (pseudocontrol) genotypes are estimated as previously described [8]

Multilocus test $p=0.425$ 
associated at age 7 to 8 years $\left(R^{2}=0.030 ; p=0.055\right.$; ESM Table 4). Results of IGF-1 protein level associations with individual SNPs are shown in Table 2. However, the multilocus IGF1 tag-SNP set did not associate with any other childhood growth or metabolic phenotype (ESM Table 4). No associations were observed between the IGF1 CA repeat and IGF-1 concentrations or any growth or metabolic phenotype (ESM Table 5).

\section{Discussion}

We used a UK birth cohort, ALSPAC, and a large family collection of type 1 diabetes to explore association with a subset of SNPs generated by in-depth resequencing of the IGFI locus. A subset of SNPs that

Table 2 IGF-1 protein levels $(\mathrm{ng} / \mathrm{ml})$ at birth and at age 7 or 8 years by genotypes of seven $I G F 1$ tag-SNPs in a representative birth cohort

\begin{tabular}{|c|c|c|c|c|c|}
\hline \multirow{2}{*}{$\begin{array}{l}\text { Parameter } \\
\text { rs35140968 }\end{array}$} & \multirow[t]{2}{*}{$n$} & \multicolumn{3}{|c|}{ Genotype (\%) } & \multirow{2}{*}{$\begin{array}{l}p \\
\text { value }\end{array}$} \\
\hline & & I/D (58) & I/I (35) & $\mathrm{D} / \mathrm{D}(7)$ & \\
\hline At birth & 315 & $88.1(2.8)$ & $91.1(3.6)$ & $105.0(8.9)$ & 0.179 \\
\hline $\begin{array}{l}7 \text { or } \\
8 \text { years }\end{array}$ & 547 & $147.8(2.9)$ & $\begin{array}{r}147.3 \\
(3.9)\end{array}$ & $157.4(9.1)$ & 0.581 \\
\hline rs6214 & & G/G (34) & G/A (50) & $\mathrm{A} / \mathrm{A}(16)$ & \\
\hline At birth & 305 & $88.6(3.6)$ & $87.7(3.2)$ & $\begin{array}{r}102.43 \\
(5.30)\end{array}$ & 0.048 \\
\hline $\begin{array}{l}7 \text { or } \\
8 \text { years }\end{array}$ & 556 & $144.1(4.0)$ & $\begin{array}{r}148.9 \\
(3.1)\end{array}$ & $\begin{array}{r}155.83 \\
(5.70)\end{array}$ & 0.239 \\
\hline rs3730220 & & A/A (38) & $\mathrm{A} / \mathrm{T}(54)$ & $\mathrm{T} / \mathrm{T}(9)$ & \\
\hline Birth & 299 & $94.1(3.8)$ & $88.6(2.9)$ & $89.6(7.4)$ & 0.509 \\
\hline $\begin{array}{l}7 \text { or } \\
8 \text { years }\end{array}$ & 548 & $152.0(3.8)$ & $\begin{array}{r}145.7 \\
(3.0)\end{array}$ & $141.8(8.1)$ & 0.331 \\
\hline rs6219 & & G/G (84) & */A (16) & & \\
\hline Birth & 300 & $91.0(2.4)$ & $85.0(5.7)$ & & 0.329 \\
\hline $\begin{array}{l}7 \text { or } \\
8 \text { years }\end{array}$ & 547 & $150.1(2.5)$ & $138.8(5.8)$ & & 0.072 \\
\hline rs2946831 & & $\mathrm{T} / \mathrm{T}(89)$ & */G (11) & & \\
\hline Birth & 294 & $90.0(2.3)$ & $95.2(7.2)$ & & 0.501 \\
\hline $\begin{array}{l}7 \text { or } \\
8 \text { years }\end{array}$ & 541 & $148.0(2.4)$ & $153.9(7.1)$ & & 0.432 \\
\hline rs3730204 & & $\mathrm{T} / \mathrm{T}(97)$ & */C (3) & & \\
\hline Birth & 294 & $\begin{array}{c}111.3 \\
(13.5)\end{array}$ & $90.3(2.3)$ & & 0.126 \\
\hline $\begin{array}{l}7 \text { or } \\
8 \text { years }\end{array}$ & 548 & $\begin{array}{c}173.8 \\
(12.9)\end{array}$ & $147.5(2.3)$ & & 0.046 \\
\hline rs12579108 & & C/C (97) & */A (3) & & \\
\hline Birth & 301 & $90.0(2.2)$ & $101.4(12.1)$ & & 0.358 \\
\hline $\begin{array}{l}7 \text { or } \\
8 \text { years }\end{array}$ & 554 & $147.6(2.3)$ & $176.8(15.9)$ & & 0.017 \\
\hline
\end{tabular}

Values are mean (SE) for IGF-1 concentration and per cent for genotype

*Additive models, adjusted for age and sex effectively predicted the genotype of the remainder was subsequently genotyped in these cohorts [9]. We report no evidence to support the hypothesis that genetic variation in $I G F 1$ is associated with major susceptibility to type 1 diabetes. However, genetic variation in this locus may modestly influence circulating IGF-1 concentrations, at least at birth and during childhood.

Prior studies examining the role of genetic variation in $I G F 1$ in predisposition to common human disease have focused on a microsatellite in the region $5^{\prime}$ to $I G F 1$. This variant has been inconsistently associated with adult height and type 2 diabetes [6,7]. Perplexingly, the same allele has been associated with high [6] and low [7] IGF-1 concentrations. It is possible that other common genetic variants, in different degrees of linkage disequilibrium with this variant, alter IGF-1 concentrations and explain the discrepancy in the published studies.

We found no association between this microsatellite and circulating IGF-1 concentrations, growth or type 1 diabetes. To exclude the possibility that other polymorphisms in the gene predispose to disease, we undertook a systematic analysis of $I G F 1$ gene variation using tagging SNPs [8]. Our relatively large white type 1 diabetes family collection of European ancestry provided $\sim 84 \%$ power to detect a causal allele for type 1 diabetes predisposition with MAF= 0.1 and OR of 1.2 at the $5 \%$ significance level. The study was therefore adequately powered to detect weak predisposition to type 1 diabetes conferred by $I G F 1$. We did not directly examine whether these variants alter the age at diagnosis of type 1 diabetes, since there was no primary evidence of association.

The possibility remains that variation in $I G F 1$ could alter insulin secretion or action as well as childhood growth. Therefore, to examine these associations, we adopted the same strategy in an established birth cohort. While we demonstrate that common genetic variation in IGFI modestly influences circulating IGF-1 concentrations at birth and during childhood, we did not find a major contribution of $I G F 1$ to birthweight, growth or response to oral glucose. It remains possible that maternal $I G F 1$ genotypes that influence maternal metabolism might alter birth size, but they are unlikely to significantly impact on childhood growth.

In summary, this large systematic study shows that common $I G F 1$ variants modestly influence circulating IGF1 concentrations at birth and during childhood. However, these variants are not associated with birthweight, childhood growth and insulin secretion or action. Moreover they do not alter type 1 diabetes risk.

Acknowledgements We gratefully acknowledge the participation of all of the type 1 diabetic patients and family members. We also thank the Human Biological Data Interchange and Diabetes UK for USA 
and UK multiplex families, respectively, as well as C. IonescuTirgoviste and C. Guja for the Romanian families, D. Undlien for the Norwegian families and D. Savage for the Northern Ireland families. Thanks also to GET1FIN (J. Tuomilehto, L. Kinnunen, E. Tuomilehto-Wolf, V. Harjutsalo and T. Valle) for the Finnish families and to the Academy of Finland, the Sigrid Juselius Foundation and the JDRF for funding. We are extremely grateful to all the families who took part in the ALSPAC study, the midwives for their help in recruiting them and the whole ALSPAC team, which includes interviewers, computer and laboratory technicians, clerical workers, research scientists, volunteers, managers, receptionists and nurses. The UK Medical Research Council, the Wellcome Trust and the University of Bristol provide core support for ALSPAC. We thank H. Rance, T. Hassanali, J. Hutchings, G. Coleman, S. Field, T. Mistry, K. Bourget, S. Clayton, M. Hardy, J. Keylock, P. Lauder, M. Maisuria, W. Meadows, M. Sebastian and S. Wood for preparing DNA samples. This study makes use of data generated by the WTCCC. A full list of the investigators who contributed to the generation of those data is available from www. wtccc.org.uk. Funding for the project was provided by the Wellcome Trust under award 076113. A. Vella is supported by the Mayo Clinic and by the National Institutes of Health DK078646-01. B. Heude was funded by the Danone Institute.

Duality of interest The authors declare that there is no duality of interest associated with this manuscript.

Open Access This article is distributed under the terms of the Creative Commons Attribution Noncommercial License which permits any noncommercial use, distribution, and reproduction in any medium, provided the original author(s) and source are credited.

\section{References}

1. Todd JA, Walker NM, Cooper JD et al (2007) Robust associations of four new chromosome regions from genome-wide analyses of type 1 diabetes. Nat Genet 39:857-864

2. Borg H, Gottsater A, Fernlund P, Sundkvist G (2002) A 12-year prospective study of the relationship between islet antibodies and beta-cell function at and after the diagnosis in patients with adultonset diabetes. Diabetes 51:1754-1762

3. Johansson C, Samuelsson U, Ludvigsson J (1994) A high weight gain early in life is associated with an increased risk of type 1 (insulin-dependent) diabetes mellitus. Diabetologia 37:91-94

4. Yakar S, Wu Y, Setser J, Rosen CJ (2002) The role of circulating IGF-I: lessons from human and animal models. Endocrine 19:239-248

5. George M, Ayuso E, Casellas A, Costa C, Devedjian JC, Bosch F (2002) Beta cell expression of IGF-I leads to recovery from type 1 diabetes. J Clin Invest 109:1153-1163

6. Vaessen N, Heutink P, Janssen JA et al (2001) A polymorphism in the gene for IGF-I: functional properties and risk for type 2 diabetes and myocardial infarction. Diabetes 50:637-642

7. Frayling TM, Hattersley AT, Smith GD, Ben-Shlomo Y (2002) Conflicting results on variation in the IGFI gene highlight methodological considerations in the design of genetic association studies. Diabetologia 45:1605-1606

8. Vella A, Howson JM, Barratt BJ et al (2004) Lack of association of the Ala(45)Thr polymorphism and other common variants of the NeuroD gene with type 1 diabetes. Diabetes 53:1158-1161

9. Vella A, Cooper JD, Lowe CE et al (2005) Localization of a type 1 diabetes locus in the IL2RA/CD25 region by use of tag singlenucleotide polymorphisms. Am J Hum Genet 76:773-779

10. Clayton D (1999) A generalization of the transmission/disequilibrium test for uncertain-haplotype transmission. Am J Hum Genet 65:1170 1177 